\title{
The Adoption of Geographic Information Systems in the Public Sector of Saudi Arabia: A Conceptual Model
}

\author{
Nouf Abdulaziz Alzahrani ${ }^{D},{ }^{1}$ Siti Norul Huda Sheikh Abdullah ${ }^{(D)},{ }^{1}$ Ibrahim Mohamed, ${ }^{1}$ \\ and Muaadh Mukred $\mathbb{D}^{1,2}$
}

${ }^{1}$ Faculty of Information Science and Technology, Universiti Kebangsaan Malaysia, 43600 Bangi, Selangor, Malaysia
${ }^{2}$ Sana'a Community College, Mareb Street, Hushaishia Road, Sana'a, Yemen

Correspondence should be addressed to Nouf Abdulaziz Alzahrani; p103841@siswa.ukm.edu.my and Muaadh Mukred; muaadh@ scc.edu.ye

Received 14 October 2021; Accepted 11 November 2021; Published 27 November 2021

Academic Editor: Naeem Jan

Copyright (c) 2021 Nouf Abdulaziz Alzahrani et al. This is an open access article distributed under the Creative Commons Attribution License, which permits unrestricted use, distribution, and reproduction in any medium, provided the original work is properly cited.

\begin{abstract}
The development of fuzzy sets in geographic information systems (GIS) arose out of the need to handle uncertainty and the ability of soft computing technology to support fuzzy information processing. Fuzzy logic is an alternative logical foundation coming from artificial intelligence (AI) technology with several useful implications for spatial data handling. GIS has been found to have a crucial role in the performance of public sector organizations (PSO). However, the literature shows no universal model to support and shed light on GIS adoption, which lessens the chances for effective GIS adoption and usage. Therefore, a new model is needed for successful adoption and eventual enhanced organization's performance. Thus, there is a need to investigate the factors that can bring about GIS adoption. Models for GIS adoption in literature are few and far between, and the few that exist are not applicable as they do not cover all the significant factors that can contribute to adoption success. Hence, this paper brought a GIS adoption model for PSOs to promote their performance. The model was developed through the extension of the Technology Acceptance Model (TAM) in addition to the DeLone and McLean's Success Model. The study involved interviews with ten experts in ranking the extracted factors, and data was analyzed through thematic analysis. On the basis of the obtained analysis findings, the fundamental factors were found to be significant in their effects, and GIS adoption sufficiently related to the overall performance. Thus, the study contributes to the body of knowledge by filling the gap in the literature.
\end{abstract}

\section{Introduction}

Geographic information system (GIS) has become a top field of study owing to its several applications in different organizations in various fields [1]. Studies dedicated to it have been carried out in Saudi Arabia concerning GIS improvements, uses, and developments; remote sensing; determination of rainfall; management of floods; public safety; and urban planning [2-4].

Fuzzy logic provides an approach that allows expert semantic descriptions to be converted into a numerical, spatial model to predict the location of something of interest to GIS. Thus, both topics are closely related to each other. GIS has been shown to have several benefits to different types of organizations and industries (small, medium, and large), with the five significant benefits being saving costs and increasing efficiency of the organization, optimum decision-making, enhanced communication, record-keeping efficiency, and geographical variables management [1]. Additionally, GIS can be combined with other IS frameworks present in the organization to store, control, and retrieve datasets. It can be used in applications in numerous areas.

Despite the richness of literature, a study has yet to be conducted on developing a GIS adoption model and its outcomes in the Saudi context, particularly in its public sector organizations. This highlights the impetus behind the current investigation to contribute to the extant literature on Technology Acceptance Models. Similar studies carried out in the Western countries context have had no significant 
outcomes (Cakar [5]). Based on Mukred et al. [6] study, technology adoption and transplant to another culture would result in distinct outcomes. One such study in the Saudi context was conducted by Alharbi [7], where UTAUT was used and documented to have less variance than that it had in the US, which means the application of the same model may differ in terms of its use outcomes based on culture and outcomes. In the same line of argument, Oliveira et al. [8] mentioned that each technology needs to have a tailor-made model for the context area to shed accurate light on its adoption. Each technology needs its specific variables, and thus the current study proposes a model of GIS tailored to a specific case, which is the Saudi public sector. The research contributes to validating existing theories and literature concerning technology adoption and acceptance, focusing on GIS adoption.

The proposed GIS adoption research model is developed based on existing technology acceptance theories, modified for the Saudi public sector. The study combines the following acceptance theories: Diffusion of Innovation (DOI)/Innovation Diffusion Theory (IDT), Technology Acceptance Model (TAM, TAM2), Theory of Reasoned Action (TRA), Unified Theory of Acceptance and Use of Technology (UTAUT), and lastly Enhanced Model of Innovation Adoption [9-12]. The theories mentioned above were developed to examine individual intention and behaviors when adopting new technologies, with some of the factors being determinants of technology usage at the individual level. Thus, they highlight the importance of individuals to the process and their crucial role in the organizations, working together toward goal achievement.

Technology adoption in developing countries is still in urgent need of investigation [13-17]. In the Saudi case, technology acceptance theories have been the focus of several studies, such as Al-Gahtani [18], who recommended focusing on the influence of new factors on the acceptance of new technologies. For example, GIS has been used to manage the environment and assets by keeping track of harmful contaminants and identifying the locations of police, fire trucks, and snowplows. Similarly, there has been a corresponding rise in public participation and interaction. For example, citizens communicate with local governments using web applications on the phenomenon's location, like potholes and crimes, and provide feedback on the developing policy decisions [19].

This study focuses on determining the factors that affect technology adoption, specifically GIS adoption, using a combination of theories to develop a model for factors testing among Saudi public organization employees. First, the study identifies new factors for the model development based on a thorough review of literature, after which the model is tested in government organizations. The proposed model and its testing are expected to contribute to the theory concerning technology acceptance, with a specific focus on GIS adoption.

The rest of the paper is organized as follows: GIS subsections are discussed in Section 2. The past related works are presented in Section 3, followed by factor extractions in Section 4. Finally, Section 5 is allocated for conceptual framework development, while Section 6 is devoted to the discussion and interpretations, followed by the conclusion in Section 7.

\section{Geographic Information Systems (GIS)}

GIS refers to an information system that works toward processing geographical data; it is a computer system that captures, stores, integrates, manipulates, analyzes, and displays spatially referenced data. It is also used to standardize, store, analyze, and model data for novel output and display maps and reports (output) [20].

In addition, GIS covers different spatially connected information types in software, hardware, and data capture, management, analysis, and reporting. It assists organizations in determining resolutions to issues through data understanding and sharing [21, 22].

Moreover, GIS has several definitions in the literature, among which is a system that stores, retrieves, analyzes, and displays data geographically/spatially. Thus, it is akin to a more extensive information system concept that handles geographical, spatial, or geospatial data for spatiotemporal application and geography investigation. "Geographic" is a general term described as relating to "geography"-a discipline of science that investigates lands, characteristics, inhabitants, and Earth phenomena (The American Heritage Dictionary, 2006). This paper adopts the GIS abbreviation for systems and technologies instead of geographical knowledge (GI Science), which is a more extensive umbrella covering other theoretical studies [23].

The composition of GIS includes applications like automated mapping and management of facilities and land information systems. GIS is commonly used to summarize various computer-based applications involving gathering, modifying, analyzing, and displaying geographic information with other linked services [24].

The following subsections are dedicated to presenting the GIS use, components, and system benefits.

2.1. The Areas of Geographic Information System Usage. All sciences relating to Earth-related geographical locations consider GIS as relevant. These fields include climate changes, disparities in temperature and population distribution among regions, and distribution of diseases, in light of their measurement and management [25]. In addition, GIS contributes to identifying the distribution of crime in various areas/regions, using technology to understand the dispersion of plants and animals. More importantly, GIS assists in locating and managing services and resources through Global Positioning System (GPS) [20].

Moreover, GIS is valuable to building, digging, and burying pipes and cables; locating oil; and other activities that need their geographical coordinates documented and monitored. The process tracking method assists in drawing up relevant and valuable information. It is stored in GIS, considering the entire location of activities and functions in a given area that needs to be determined. In other words, GIS is used daily to solve problems related economic regions, 
healthcare, and construction of infrastructure. Moreover, it shares data and information in a way that is impossible if the same information is gathered from individuals [26].

Innumerable organizations in almost all areas make use of GIS to create mapping to communicate, analyze, and share information and find resolutions to issues all over the globe, which has led to changes in the way things are done. Moreover, GIS is used for interpreting data visualization-as exemplified by Google Maps, a web-based GIS mapping solution for navigation in daily life. In the case of organizations, they can include geographical data into their tasks involving design, optimization, planning, and maintenance. For example, relevant data would work toward optimizing telecom processes through optimal customer-relationship management and location services. Data from GIS is also used to determine and enhance road networks through the use of data intelligence, and this contributes to keeping the roads safe and enhancing the management of traffic [27].

In addition to the above, GIS data is used to evaluate the growth of urban areas and the direction of such growth. Its effective use can set the basis for future development while considering important specifics for building success. Such data is also used in transport management, with companies enabled to plan new roads/rail routes by incorporating environmental and topical data into the GIS platform. GIS applications collect data, which is later utilized to conserve and protect natural resources and the whole environmental condition. For instance, impact reports are invaluable for evaluating the level to which issues in the environment are contributed by the GIS integration [28].

Furthermore, GIS data helps develop farming methods efficiency and soil data analysis, enhancing food production in different global areas. The use of an efficient GIS protects the environment and helps minimize risks and manage catastrophic events. Such data is also utilized in web-based navigation maps to provide the public with the required information. Web maps are kept in current condition daily based on GIS data and are extensively used [29].

On the whole, GIS is useful for mapping, telecommunication services, network services, analysis of accidents and hotspots, urban planning, and traffic management, which in turn makes it valuable for environment analysis, agricultural applications, management and minimization of catastrophes, navigation, estimates of floods, managing natural resources, taxation, banking, surveys, asset management and maintenance, geology, and even irrigation [20, 29].

Because of its varying applications, GIS data has had a profound impact on industries, businesses, and society. Without GIS data, a significant difference would be felt in our daily personal and professional lives. Moreover, GIS technologies have been increasingly transforming from a mere tool for resolving limited application problems to an element of territorial growth in public administration areas in emerging nations [30].

2.2. Geographic Information System Components. There are six components of GIS, with the network being the topmost significant component. This is because the transfer of data and digital information can only be possible through the network. Hardware is the second GIS component, and it comprises equipment required for operating GIS [26]. The third GIS component is software, and service providers like Environmental Systems Research Institute sell business packages. These programs differ from one GIS supplier to the next in light of applications, complexity, and data size. The database is the fourth GIS component within which the complete information is stored and is useable for decisionmaking and problem-solving. This is followed by budget, as the fifth GIS component, and it encapsulates budget, capability, and accuracy techniques for GIS administration and meeting the needs of stakeholders. Finally, GIS users make up the sixth component and supply and update the GIS digital data for efficient and up-to-date functionalities $[26,31]$.

One of the leading GIS software suppliers is Esri, and it generates the ArcGIS line of products-it created a webbased GIS (ArcGIS Online) and a server (ArcGIS Server) to provide solutions that are state-of-the-art through advanced technology [32]. In the past two decades, Geographical Information Systems Science is a phrase that has been reported to have different qualities (technical and intellectual) and aspects [33]. In this regard, the GIS is referred to as an application, tool, and science in three major formats [33].

The topmost significant GIS software types are desktop software, web mapping, GIS server, virtual globe, developer, and handheld GIS software. Among them, desktop GIS software is the most extensively utilized, introduced initially on PC using Microsoft Windows operating system. However, other GIS software systems have also been functional and have efficiency $[26,32]$.

2.3. The Benefits of Geographic Information System (GIS). GIS function involves integrating software, hardware, and data to acquire and manage geographic data and its analysis. The finalized geographic information is displayed so that the users can access it for an easy and quick understanding of data and decision-making [34].

Moreover, when it comes to pandemics, GIS is invaluable in examining the spatial distribution of infectious diseases [35] to combat the pandemic and enhance care quality. In addition, it has become an essential tool used to analyze and visualize the COVID-19 spread [36].

Specifically, GIS and its different modes have been utilized in the scientific research and planning of strategic healthcare activities and decision-making to map out the spread of COVID-19 in light of spatial and temporal distribution and diffusion. Plenty of helpful information has come up from the system's geographical, geospatial, and geostatistical analysis and applications that have proven valuable for interpreting the dynamics, patterns, clusters, and trends to support the planning and activities of the healthcare sector. To this end, similar types of applications have multiplied owing to the web's synergistic nature of sharing and spreading data and information. In particular, GIS has led to enhanced and refined IT capabilities, public safety, and enhanced and efficient healthcare response. GIS 
can be logically applied to monitor diseases and prepare for disasters in healthcare institutions [37].

Additionally, GIS is useful in mapping the geographical disease distribution and transmission trends and creating a spatial model of its environmental aspects and occurrences. Concerning this, Murad and Khashoggi [20] developed a GIS application to generate mapping and cluster modeling of three diseases, diabetes, asthma, and hypertension, in Jeddah, in Saudi Arabia. The authors proved the capability of GIS to assist in updating and mapping health events and to support surveillance and decision-making concerning the monitoring of health conditions and diseases.

The GIS adoption environment offers benefits like access to various spatial functions. It matches rapid development and prototyping. The approach can be used to trace and treat patients on time and adopt preemptive actions in the same area. The GIS approach can also be used to inform others about the details of the spread of the disease [38].

GIS's advantages can be categorized into six major categories: cost-saving, efficiency increase, informed decision-making, communication enhancement, efficient record-keeping, and geographical management [21, 39]. Furthermore, according to Margolis and Pauwels [21], GIS can be combined with an IS model.

Different areas also leverage GIS for storing, controlling, and retrieving datasets in what is referred to as a layer-a collection of information regarding roads, seas, buildings, and the like. Layers are stored in a GIS database based on coordinates. When they are in one location, with the exact coordinates, they are connected in what is referred to as spatial joins between datasets. These joins can assist in informed decision-making based on stored data in the database. This may be exemplified by the location of roads that may be flooded because of a specific river with similar geographical coordinates [1].

Other government sectors have also used comparable technologies, with the Saudi Post being one of the most notable examples. The National Address Project in 2010 encouraged enterprises to embrace such technology by pressing them to leverage project outcomes through agreements with various government and private sectors. This also made it easier to get spatial data via the Internet, notably in the circles of system and application developers, to ease the use of accurate and authentic maps and spatial data $[40,41]$.

\section{Past Related Works on GIS Adoption and Research Gap}

GIS diffusion is distinct from other technology diffusion in extant literature owing to one significant reason; technology in this study is adopted at the organization level rather than at the individual level. Consequently, the need to study the adoption of GIS by the organization and the way it is diffused in the organization needs examining to meet the organization's needs.

Regardless of the innumerable studies conducted concerning the diffusion of GIS technology, only a few were developed for the nation. For instance, Eria and McMaster
[42] focused on GIS adoption in Uganda through a mixed data collection and analysis approach underpinned by the Diffusion of Innovation (DOI) model. They found that GIS adoption among the Ugandan institutions took place in a classic diffusion pattern aligned with the propositions of the diffusion theory. The decision to adopt GIS was made based on its relative advantage over and alignment with current technologies. Because of bureaucratic intervention and patronage-based societal norms, the adoption rate followed an S-shaped diffusion curve.

Developing countries' governments have been undergoing continuous reforms that have urged their adoption and usage of GIS with other ICTs for the governance of urban areas. However, few studies have been carried out on GIS spatial knowledge construction in countries other than those in the West, as highlighted in Mukherjee's research [22], where he examined Surat Municipal Corporation (SMC). This corporation is one of India's leading urban local bodies, implementing e-governance strategies that entailed spatial information and GIS. Alkhofani [15] used an integrated method to study the spatial knowledge construct via GIS based on literature and adoption and diffusion studies. It was demonstrated that such a structure is formed not only by the corporation's role in finding a niche within the government's priorities and agendas but also by influential players who have played a leading role in bringing about innovation and dynamic changes.

Abousaeidi et al. [43] examined GIS modeling adoption in a similar study line to determine the fastest routes to deliver fresh vegetables. Fresh vegetables lose their freshness during regular routes because of the time consumed and the environment's temperature. Despite this, only a narrow focus has been placed on transportation issues in most Kuala Lumpur areas, and because perishable food generally has a short shelf life, timely delivery has a significant influence on delivery costs. Thus, the selection of the proper routes would minimize the costs of total transportation. The study employed a regression model to determine the route choice parameters concerning the fastest fresh vegetable delivery. The authors adopted ArcGIS software with network analyst extension to resolve complex network issues. Their conclusion mapped the timeliest routes with the shortest delivery time based on all variables examined.

Hebert and Root [44] examined and discussed the potential role of GIS in infection control in healthcare environments. The authors provided an overview of the GIS role in public health and reviewed work concerning the applications of the method in the setting. Potential opportunities and challenges for GIS adoption for infection prevention were enumerated, and literature concerning the topic was reviewed to demonstrate GIS use in the healthcare workplace. The complexity discussion was documented using the nonadoption, abandonment, scale-up, spread, and sustainability (NASSS) framework. The authors then obtained the challenges and opportunities from the process, and multiple challenges involving the domains of technology, organization, and adaptation were underlined. A transdisciplinary method was proposed to address the challenges, and more studies involving prospective, reproducible clinical trials for 
the optimal assessment of the potential influence and effectiveness of GIS in hospital settings were called for. There are many GIS adoption studies in various countries listed in Table 1.

GIS technology has drawbacks and flaws such as a lack of data, a lack of GIS training skills, errors in geocoding, and structural limitations in its use due to personal data confidentiality and privacy. This demonstrates that GIS technology adoption varies by organization, even among those performing the same activities.

In the case of Saudi public sector organizations, efforts are being made to improve performance and effectiveness through the use of IT advances, including GIS. In this regard, most IT application initiatives are limited to individual departments rather than the entire institution's operations. As a result, applications and databases are fragmented. Consequently, for adoption success, public sector organizations require a guiding model to follow. Public sector organizations, on the other hand, have similar business functions and structures. In this regard, a general model is required to guide their GIS application adoption as soon as possible. This research aims to develop and propose a GIS adoption model for organizations in the Saudi public sector. First, the paper reviewed the literature for the top factors that determine GIS adoption. Then, they were used to develop a model that is tailor-made for Saudi public sector organizations. The GIS adoption model contains the requirements for organizations in their quest to adopt the system, and it highlights the role that other technologies play in supporting it. Nine major factors are contained within the model: information quality, system quality, service quality, change management, competitiveness pressure, pandemic pressure, security, perceived ease of use, and perceived usefulness. The factors were examined in terms of their effects on GIS adoption and the public organizations' overall performance. The details of factors extractions and model constructions are discussed in the coming sections.

\section{Factors Extractions}

Extant literature has delved into factors that influence the attitude of individuals toward innovation adoption [55], and based on the reviewed relevant studies, several factors have this potential $[10,11]$.

Studies in literature have adopted several methods to determine the GIS adoption factors, with the main ones enumerated in Table 2 . In addition, every method with its strengths and weaknesses, among other details, was mentioned in Khandelwal and Ferguson [67] study, as depicted in the table.

Figure 1 depicts the study methodology, which is divided into three stages: conducting a thorough literature review and identifying the critical factors; consulting experts on GIS factors, emphasizing the most important; and then using them to develop the study framework.

The most commonly used method for determining the factors influencing GIS technology adoption was identified as the literature review method $[69,70]$. Extraction of factors entails several steps, beginning with reviewing the literature and progressing to interviews with experts.

4.1. Factors from the Intensive Literature Review. Technology adoption studies, particularly GIS, were reviewed to identify the general factors used by the authors, and from the review, 57 factors were highlighted; these factors are tabulated in Table 3.

The authors conducted a content-based literature review through Google Scholar, Scopus, and Web of Science databases. Several keywords were used in this regard such as "GIS adoption," "GIS factors," "GIS models," "GIS and organization's performance," "GIS in Saudi Arabia," and "GIS benefits."

Frequency depicts the number of times the factors are cited in literature; however, this does not imply their ordinary and common nature $[71,72]$. Table 4 tabulates the 20 factors of GIS adoption based on the frequency table.

Aside from Table 4, the other factors were not as frequently cited and were thus not included in the table.

4.2. Factors Ranked by Experts. The above factors were exposed to experts to obtain their feedback on them in light of their influence on the integrated GIS. Consequently, nine factors were viewed to be the significant factors that influence behavioral intention to use GIS and, in fact, actual usage. This study followed Hawking and Sellitto [73] and Ahmad and Cuenca [74] studies to determine the significance of the factors (refer to Table 5).

The experts are selected from related fields such as technology adoption, GIS engineers, IS data analysts, and academicians. Table 6 shows the profile for the experts.

Experts were interviewed to learn about their perspectives on GIS adoption. Along with the interviews, the experts were also asked to answer various questions in a questionnaire about the items in each factor. A total of nine factors were identified as the most important factors of behavioral intention to use GIS and, ultimately, its role in improving organizational performance.

This study proposes a GIS model, which encapsulates determinants of intention to adopt GIS and the adoption's perceived organizational performance. The study uses variables from DeLone and McLean (informational quality, system quality, and service quality), variables from TAM (perceived ease of use, perceived usefulness), and additional factors from literature (change management, security, competitiveness pressure, and pandemic pressure) as recommended by experts.

\section{Conceptual Framework Development}

In this paper, ten hypotheses were formulated to propose a framework on the influence of factors on the behavioral intention to adopt GIS; nine propositions were formulated for each of the exogenous factors. The final proposition (P10) addresses the influence of GIS adoption on organizational performance. In contrast, the first nine hypotheses address the effect of GIS factors, namely, system quality, 
TABle 1: Past related work on GIS adoption.

\begin{tabular}{|c|c|c|c|}
\hline No. & Author & Country & Gap \\
\hline 1 & {$[42]$} & Uganda & Scarce research has been done in the developing countries \\
\hline 2 & {$[22]$} & India & Scarce research has been done in the developing countries \\
\hline 3 & {$[43]$} & Malaysia & There is a need for more investigation of GIS adoption \\
\hline 4 & {$[45]$} & Malaysia & The need for more investigation of GIS adoption \\
\hline 5 & {$[46]$} & Turkey & There is a need for more investigation of GIS adoption \\
\hline 6 & {$[47]$} & Thailand & There is a need for more investigation of GIS adoption \\
\hline 7 & {$[30]$} & Ukraine & GIS is useful and needs to be implemented in different fields \\
\hline 8 & {$[48]$} & Sweden & GIS needs more research focus \\
\hline 9 & [49] & Mozambique & GIT adoption is still in its early stage and needs more research to be done \\
\hline 10 & {$[50]$} & India & $\begin{array}{c}\text { GIS could be integrated with other tools to help many organizations. However, the research is still in the early } \\
\text { stage }\end{array}$ \\
\hline 11 & {$[51]$} & Saudi Arabia & GIS is useful and could be implemented in different fields \\
\hline 12 & {$[52]$} & Saudi Arabia & There is a need for more investigation, especially at the organizational level \\
\hline 13 & {$[53]$} & United States & $\begin{array}{l}\text { The GIS adoption is still in its infancy and needs more attention. Therefore, there should be new research to } \\
\text { be conducted and new factors to be included }\end{array}$ \\
\hline 14 & {$[54]$} & Saudi Arabia & $\begin{array}{l}\text { The GIS adoption is still in its infancy and needs more attention. Therefore, there should be new research to } \\
\text { be conducted and new factors to be included }\end{array}$ \\
\hline 15 & [44] & United States & More research should be conducted to examine the impacts of GIS adoption \\
\hline
\end{tabular}

TABle 2: Techniques for factor extractions.

\begin{tabular}{lc}
\hline Research method & Authors \\
\hline Action-research & {$[56]$} \\
Case studies & {$[57]$} \\
Structured interviewing & {$[58]$} \\
Scenario analysis & {$[59]$} \\
Multivariate analysis & {$[60]$} \\
Literature review & {$[61]$} \\
Group interviewing & {$[57]$} \\
Focus groups & {$[62]$} \\
Delphi technique & {$[63,64]$} \\
Combination of methods & {$[65,66]$} \\
\hline
\end{tabular}

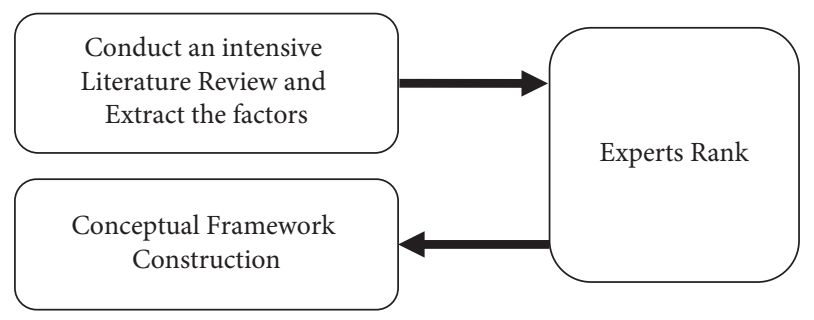

FIgURE 1: The methodology of the study as adopted from [68].

information quality, service quality, change management, competitiveness pandemic pressure, perceived ease of use, perceived usefulness, and security, on behavioral intention of adopting GIS. The factors must be aligned together to understand GIS adoption and, thus, such adoption's effect on the performance of the organization. GIS benefits cannot be fully reaped without matching the factors. The primary study constructs and their corresponding hypotheses are depicted in Figure 2 and Table 7.

Table 7 shows the propositions that the study comes up with.

TAM is the most extensively used model compared to the rest of the adoption models in the literature [75], and it has been examined in different contexts and versions. Lee
[76] claimed that it is the cited model for shedding light on technology acceptance in the past 20 years. Its intentionbased model was exclusively developed for accepting IT.

When it comes to technology acceptance, TAM has been strongly established and well tested, and it has a robust ability to predict users' acceptance [77]. Users with different experience levels and various systems have been tested using TAM. It has been proved to have a high success rate in predicting technology use (40-70\%) [78, 79].

In the context of public sector organizations, TAM was employed by many studies in the literature [80-82]. Specifically, in GIS adoption, TAM has been adopted by prior studies to examine acceptance/adoption with modifications to suit individual study objectives [79, 83-86].

Thus, in this study, TAM [9] is adopted as an underpinning model, with perceived ease of use (EAU) and perceived usefulness (PU) viewed as factors that affect intention to adopt GIS.

Furthermore, organizations generally adopt technologies for their employees' acceptance and usage. Therefore, in the present study, the attributes and characteristics of staff that affect their adoption of GIS are examined for enhanced performance of the whole organization. Based on the literature, models fall short of successfully explaining GIS adoption. This study addresses this literature gap by adopting theories and models to look into the adoption of GIS. The study proposes a GIS model capable of obtaining performance by analyzing a variety of factors that affect behavioral intention of adopting GIS. In sum, the study's underpinning models include TAM, and DeLone and McLean's IS Success Model, from which the study factors are extracted.

\section{Discussion and Interpretation}

The first exogenous latent variable in the brought forward conceptual model is system quality, which is described as the IS measurements [87], and it generates output in the 
TABLE 3: Extracted factors from the intensive literature review.

\begin{tabular}{|c|c|c|}
\hline Group of factors & Factors & Total of factors \\
\hline Individual & $\begin{array}{l}\text { Attitude, subjective norm, self-efficacy, satisfaction, motivation, personal beliefs, education, } \\
\text { age, experience, gender }\end{array}$ & 10 \\
\hline Technological & $\begin{array}{l}\text { Trust, effort expectancy, perceived usefulness, features used, compatibility, privacy, } \\
\text { information technology challenges, service quality, perceived ease of use, technological } \\
\text { readiness, efficiency, reliability, IT infrastructure, interactivity, information quality, } \\
\text { responsiveness, system quality }\end{array}$ & 17 \\
\hline Organizational & $\begin{array}{c}\text { Resources available, perceived financial cost, top management support, standardization, } \\
\text { change management, outsourcing, social influence, facilitating conditions, training, effective } \\
\text { communication }\end{array}$ & 10 \\
\hline Environmental & $\begin{array}{c}\text { Clear vision and planning, government role, policy, competitiveness pressure, security } \\
\text { concerns, laws and legislations, pandemic pressure }\end{array}$ & 7 \\
\hline $\begin{array}{l}\text { Behavioral intention to } \\
\text { use/adopt }\end{array}$ & $\begin{array}{c}\text { Usage intentions, habit, intention to use, intention, user involvement, relationship with } \\
\text { developers }\end{array}$ & 6 \\
\hline Use/adopt GIS & $\begin{array}{l}\text { Improved efficiency, user satisfaction, performance, output quality, organizational } \\
\text { competence, perceived benefits, decision-making }\end{array}$ & 7 \\
\hline Total & & 57 \\
\hline
\end{tabular}

TABLE 4: Ranking of the extracted factors from literature review.

\begin{tabular}{lcc}
\hline No. & Factor & Total \\
\hline 1 & Top management support & 33 \\
2 & User involvement & 25 \\
3 & Perceived usefulness & 30 \\
4 & Information quality & 28 \\
5 & Effective communication & 28 \\
6 & Clear vision and planning & 27 \\
7 & Pandemic pressure & 10 \\
8 & Perceived financial cost & 25 \\
9 & Change management & 25 \\
10 & System quality & 25 \\
11 & Competitiveness pressure & 23 \\
12 & Security & 23 \\
13 & Policy & 23 \\
14 & Service quality & 20 \\
15 & Government role & 19 \\
16 & Performance & 17 \\
17 & Intention to use & 17 \\
18 & Laws and legislations & 17 \\
19 & Facilitating conditions & 16 \\
20 & Perceived ease of use & 28 \\
\hline
\end{tabular}

TABLE 5: List of factors recommended by experts.

\begin{tabular}{lcc}
\hline No. & Factor & Rank out of 5 \\
\hline 1 & System quality & 4.2 \\
2 & Pandemic pressure & 4.3 \\
3 & Information quality & 4.2 \\
4 & Change management & 4.3 \\
5 & Perceived ease of use & 4.4 \\
6 & Security & 4 \\
7 & Perceived usefulness & 4.3 \\
8 & Service quality & 4.1 \\
9 & Competitive pressure & 4 \\
10 & Intention to use & 4.1 \\
11 & Performance & 4.3 \\
\hline
\end{tabular}

information processing system. It also covers the processing quality of IS, with software and data components, and gauges the technical soundness of the system [88]. The system quality is proposed to significantly affect IS effectiveness, which is the level to which IS can realize what it is meant to do. In GIS, system quality can be measured using appropriate access reports/services, and therefore the study proposes the following hypotheses for testing;

P1: System quality has a positive relationship with behavioral intention to adopt GIS.

With regard to information quality, it is described as a successful level to which IS meets the purpose of its creation [89]. Poor quality information can negatively affect the organization's tactics, strategies, and operations [88, 89]. The attributes of system quality are invaluable in assessing information processing systems, while those of informational quality assist in assessing the input and output of the system [90].

The generated quality of information from the system also has a hand in the perception of the system's usefulness; in other words, information quality has a significant relationship with system use according to the empirical findings reported by Mukred and Yusof [89]. P2: Information quality has a positive relationship with behavioral intention to adopt GIS.

The third factor proposed in the conceptual framewogure

rk is service quality. It refers to the difference between the user's normative expectations level of the service and his/her perception of the actual service performance level [90].

DeLone and McLean [91] updated the model viewed service quality as a new model dimension, and they categorized all the effect measures into one effect, known as a net benefit. The present study assesses the GIS service quality in light of the timely service provision, exemplary services, accurate services, and complete services. This study tests the following related proposition for this construct.

P3: Service quality has a positive relationship with behavioral intention to adopt GIS. 
TABLE 6: Experts biography.

\begin{tabular}{lccc}
\hline No. & Gender & Field and expertise & Affiliation \\
\hline 1 & Female & Information science & King Saud University \\
2 & Male & Technology adoption & University of King Abdulaziz \\
3 & Male & Technology adoption & Ministry of Transport \\
4 & Male & Technology adoption & Saudi Geological Survey \\
5 & Male & Technology adoption and IS & State Properties General Authority \\
6 & Female & Computer science & Ministry of Transport \\
7 & Male & Information science & Department of Geography, Umm Al-Qura University \\
8 & Male & Engineering & Saudi Geological Survey \\
9 & Male & Engineering & Saudi Geographical Society \\
10 & Male & Engineering & Ministry of Transport \\
\hline
\end{tabular}

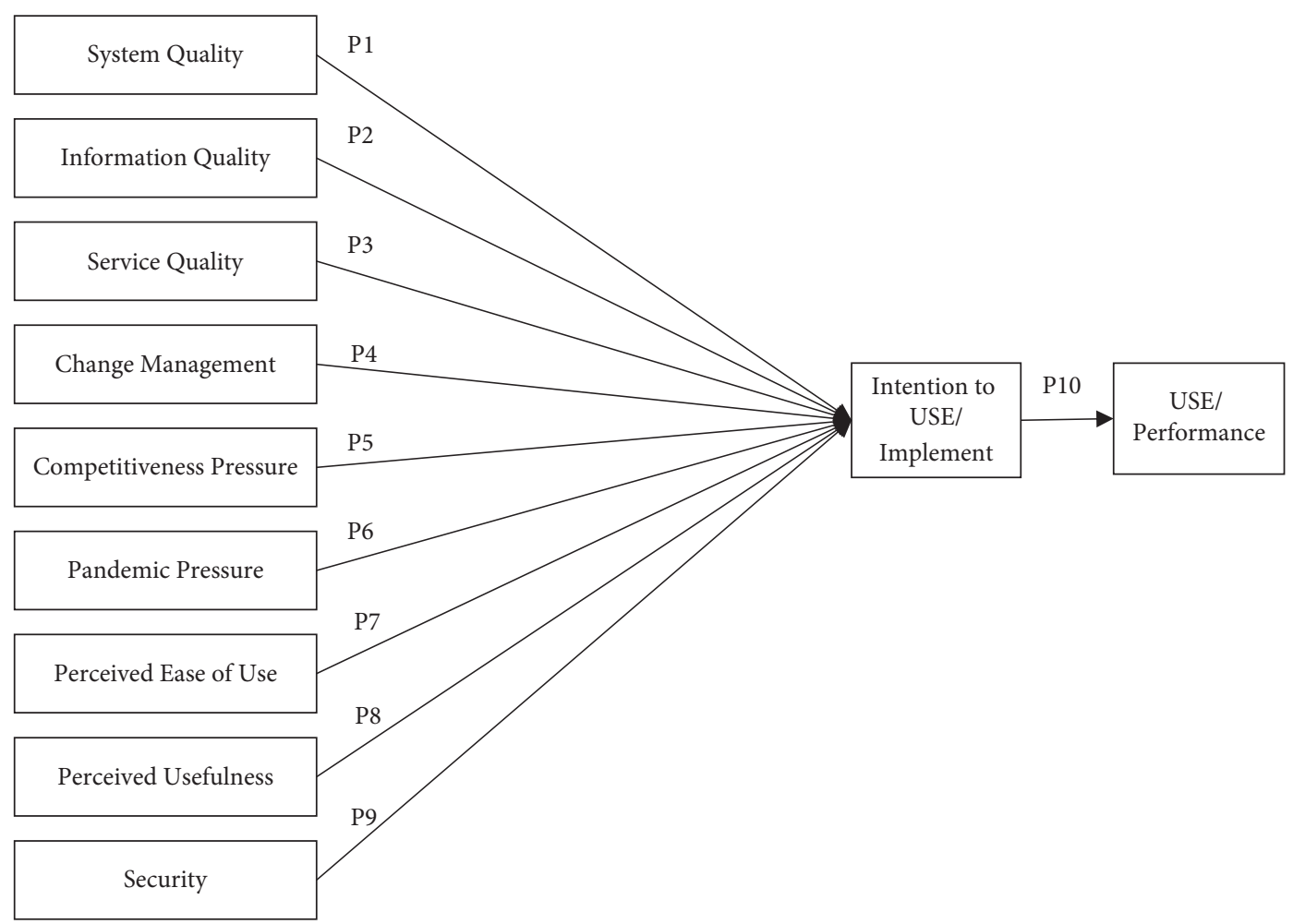

FIGURE 2: GIS proposed conceptual model and proposition.

TABLE 7: Research propositions.

\begin{tabular}{lc}
\hline No. & Proposition \\
\hline P1 & System quality has a positive relationship with the intention to use/implement GIS \\
P2 & Information quality has a positive relationship with the intention to use/implement GIS \\
P3 & Service quality has a positive relationship with the intention to use/implement GIS \\
P4 & Change management has a positive relationship with the intention to use/implement GIS \\
P5 & Competitiveness pressure has a positive relationship with the intention to use/implement GIS \\
P6 & Pandemic pressure has a positive relationship with the intention to use/implement GIS \\
P7 & Perceived ease of use has a positive relationship with the intention to use/implement GIS \\
P8 & Perceived usefulness has a positive relationship with the intention to use/implement GIS \\
P9 & Security has a positive relationship with the intention to use/implement GIS \\
P10 & Intention to use/implement GIS has a positive relationship with use/performance \\
\hline
\end{tabular}

Moreover, change management is among the top evidence factors mentioned in the discussion, and the GIS application proves the changes wrought in the company. Essentially, change management is a method used for effective management necessitating the shift from traditional models to current models. Change management is required for GIS as the employees need to be prepared to adapt to the changes. The 
organization needs to have a formal change management initiative for issues resolution, such as employee resistance, redundancies, errors, and ambiguities, relating to implementing the new model [92]. Workinvolved employees will be more privy to the benefits, enabling them to be more adept at using the new model, [93] and therefore the following hypotheses are proposed.

P4: Change management has a positive relationship with behavioral intention to adopt GIS.

Increased competitiveness at the local and global level is another factor that pressures organizations to seek ways to enhance their efficiency and effectiveness through strategies adoption [94]. In other words, dynamic competition and technological advancements throughout the world and digital technology developments have given governments a reason to take advantage of new methods to thrive. This has, in turn, led to the shift of government services from using traditional methods to using e-methods [95], and based on the above discussion of prior studies, this study proposes the following hypotheses.

P5: Competitiveness pressure has a positive relationship with behavioral intention to adopt GIS.

Still, another factor affecting the use of new technology is pandemic pressure, and using GIs calls for information and knowledge to be inculcated in users for solving various issues. User's training has a significant role in determining the overall GIS use success $[96,97]$. Users armed with the knowledge of the new model concepts are more capable of being positively inclined to use it, are not adamant about resisting its use, and readily accept it. The involvement of users also helps in GIS configuration analysis, data conversion, and model testing [98].

Pandemic pressure requires an urgent training and is referred to as something that is a must for system adoption and for garnering benefits, and thus this study tests the following hypotheses.

P6: Pandemic pressure has a positive relationship with behavioral intention to adopt GIS.

In the TAM, perceived ease of use refers to an individual's conviction that utilizing a particular technology will be effortless [75]. Perceived ease of use refers to the manager's and employee's opinion of the minimal effort required to utilize GIS. Both intention to use and adoption are influenced by perceived ease of use [12]. Furthermore, several studies proved the significant effect of perceived ease of use on intention to use the system $[99,100]$. Perceived ease of use significantly impacts intention to adopt the system [100]. Therefore, the following proposition is proposed to be tested.

P7: Perceived ease has a positive relationship with behavioral intention to adopt GIS.

Additionally, perceived usefulness refers to the degree to which an individual believes that utilizing a certain system will improve his or her job performance [75]. In a parallel study, Vathanophas et al. [101] used TAM to assess naval officers' approval of Internet use. The data indicate that perceived utility has a major effect on users' intentions. Additionally, Venkatesh et al. [12] discovered that performance expectancy (perceived usefulness) and effort expectancy (perceived ease of use) are significant determinants of behavioral intention to adopt an information system.

Perceived usefulness is defined in this study as managers' and employees' perceptions of the GIS's usefulness. This characteristic was evaluated in terms of the system's capacity to improve performance, productivity, and effectiveness. Enormous empirical research has demonstrated that perceived usefulness influences an individual's inclination to utilize and adopt a system [102].

On the basis of the foregoing reasoning, the following proposition is put to the test.

P8: Perceived usefulness has a positive relationship with behavioral intention to adopt GIS.

Finally, even if the information system's security is started at the top, it affects every division of the firm. All of the company's records are accessible at any time and from any location. Because there is no way to know for sure if an organization is trustworthy when it comes to keeping confidential information and promoting information security, institutions such as banks, financial institutions, insurance companies, hospitals, and laboratories all keep personal and confidential records and credit card information that must be provided for Internet transactions [103].

The present study describes security as the features and processes that are followed in dealing with organizations' assets.

In connection with the above, several studies revealed that security significantly influences intention to adopt technologies [104, 105]. Based on this discussion, the following proposition is proposed by the researchers.

P9: Security has a positive relationship with behavioral intention to adopt GIS.

GIS adoption requires a plan and vision that could assist in directing the project and in developing a business model; in other words, the organizational strategy needs to be adopted after the implementation phase $[72,106]$. The initiative needs to be viewed as the top priority, and decision-making relating to it needs to be conducted before its implementation through the management members' feedback [107].

Moving on to intention to use, we define it as the intention of the user to use new technology and the probability that the user will make use of a particular system [108]. TAM posits that intention to use influences actual new system use, and this was evidenced by Mukred et al. [82], who indicated that intention to behave determines actual usage. Therefore, it can be 
stated that intention to use technology determines intention to adopt it.

Comparatively, business performance is the organization's responsibility to the shareholders and maximization of profits [96]. Therefore, as mentioned in prior studies, business performance conceptualization requires two dimensions: financial performance and market performance.

Evidently, behavioral intention directly affected GIS adoption [109] and thus, based on the discussion above, this study proposes the following proposition.

P10: Behavioral intention to adopt GIS has a direct significant and positive effect on Saudi's private sector GIS performance.

\section{Conclusion}

GIS plays a vital role in business management, which is why it is increasingly regarded as a key tool for improving organizational performance. However, determining the factors that contribute to new technology adoption is necessary, so the study examines the major issues related to the significant factors in adopting GIS among public organizations in Saudi Arabia. The focus of this study is on the level of importance of factors to the adoption of GIS; these factors have been obtained from theories and supported by reviewed literature and expert recommendations.

The underpinning theories for the study were TAM, and DeLone and McLean's Success Model. TAMs successfully explain $40 \%$ of the variance in behavioral intentions [98]. The model is appropriate for use in this study because TAM was used in IS adoption studies involving large-sized firms and institutions.

The paper went on to discuss the role of GIS in improving organizational performance as well as the significance of its model for adoption efficiency and effectiveness. Based on the reviewed literature, the paper detailed related system adoption issues in various contexts and the major role of GIS in organizations and as a firm asset promoting their performance as guided by the GIS adoption model.

Based on the reviewed literature and theories, the paper concluded a lack of studies concerning GIS adoption in public sector organizations. Thus, a model to guide such adoption is still lacking. The paper enumerated the limitations and gaps in the literature on GIS, emphasizing the importance of developing a GIS adoption model for successful adoption.

This study is expected to enrich the body of knowledge in the technology adoption field. The study comes up with new factors that might influence the GIS adoption in public sector organizations. Based on the literature review and experts, new factors and a new model are proposed. Nine major factors are contained within the model: information quality, system quality, service quality, change management, competitiveness pressure, pandemic pressure, security, perceived ease of use, and perceived usefulness.

Finally, the paper emphasizes the need for additional research into the role of GIS in performance in order to develop an effective GIS adoption model. This study aims to create a model to guide GIS adoption and address issues that may arise during this process. According to the studies reviewed, there is a significant relationship between GIS adoption success and an effective model to guide such adoption.

\section{Data Availability}

Data are included in the manuscript.

\section{Conflicts of Interest}

The authors declare that they have no conflicts of interest.

\section{Acknowledgments}

The authors would like to express their gratitude to the Malaysian and Saudi Arabian experts involved in this work. The authors also thank the Faculty of Information Science and Technology at Universiti Kebangsaan Malaysia for allowing them to perform this study.

\section{References}

[1] S. Alkobaisi, W. D. Bae, P. Vojtěchovský, and S. Narayanappa, "An interactive framework for spatial joins: a statistical approach to data analysis in GIS," GeoInformatica, vol. 16, no. 2, pp. 329-355, 2012.

[2] A. S. El-Hames, M. Al-Ahmadi, and N. Al-Amri, "A GIS approach for the assessment of groundwater quality in Wadi Rabigh aquifer, Saudi Arabia," Environmental Earth Sciences, vol. 63, no. 6, pp. 1319-1331, 2011.

[3] D. Kheder, "Application of remote sensing and GIS for flood risk assessment: a case study of Al Kharj Valley Saudi Arabia," International Journal of Scientific Engineering and Research, vol. 5, pp. 110-115, 2014.

[4] S. H. Mahmoud and A. A. Alazba, "Identification of potential sites for groundwater recharge using a GIS-based decision support system in Jazan region-Saudi Arabia," Water Resources Management, vol. 28, no. 10, pp. 3319-3340, 2014.

[5] B. Cakar, Factors Affecting Police Officers' Acceptance of GIS Technologies: A Study of the Turkish National Police, University of North Texas, Denton, TX, USA, 2011.

[6] M. Mukred, Z. M. Yusof, U. A. Mokhtar, and F. Fauzi, "Taxonomic framework for factors influencing ERMS adoption in organisations of higher professional education," Journal of Information Science, vol. 45, no. 2, pp. 139-155, 2019.

[7] S. T. Alharbi, "Trust and acceptance of cloud computing: a revised UTAUT model," in Proceedings of the Computational Science and Computational Intelligence (CSCI), March 2014.

[8] T. Oliveira, M. Thomas, and M. Espadanal, "Assessing the determinants of cloud computing adoption: an analysis of the manufacturing and services sectors," Information \& Management, vol. 51, no. 5, pp. 497-510, 2014.

[9] V. Venkatesh, M. G. Morris, G. B. Davis, and F. D. Davis, "User acceptance of information technology: toward a unified view," MIS Quarterly, vol. 27, no. 3, pp. 425-478, 2003.

[10] A. Alzighaibi, M. Mohammadian, and M. Talukder, "Factors affecting the adoption of GIS systems in the public sector in Saudi Arabia and their impact on organizational 
performance," Journal of Geographic Information System, vol. 8, no. 3, pp. 396-411, 2016.

[11] M. Talukder and A. Quazi, "The impact of social influence on individuals' adoption of innovation," Journal of Organizational Computing \& Electronic Commerce, vol. 21, no. 2, pp. 111-135, 2011.

[12] V. Venkatesh, J. Y. Thong, and X. Xu, "Consumer acceptance and use of information technology: extending the unified theory of acceptance and use of technology," MIS Quarterly, vol. 36, no. 1, pp. 157-178, 2012.

[13] H. M. Oumran, R. B. Atan, R. N. Haizan Binti Nor, S. B. Abdullah, and M. Mukred, "Knowledge management system Adoption to improve decision-making process in higher learning institutions in the developing countries: a conceptual framework," Mathematical Problems in Engineering, vol. 2021, Article ID 9698773, 15 pages, 2021.

[14] A. Haddad, A. A. Ameen, and M. Mukred, "Toward examining the impact of intention of use on the success of big data adoption via organization readiness factor," in Proceedings of the 1st International Conference on Management and Human Science, Kuala Lumpur, Malaysia, 2017.

[15] W. Alkhofani, "The significant factors for the implementation of digital records management initiatives in Yemen: a conceptual framework," International Journal of Technical Innovation in Modern Engineering \& Science (IJTIMES), vol. 5, no. 3, pp. 1066-1073, 2019.

[16] B. Hawash, "Factors affecting internet of things (IoT) adoption in the Yemeni oil and gas sector," in Proceedings of the 2021 International Conference of Technology, Science and Administration (ICTSA), 2021.

[17] B. Hawash, "A conceptual framework for the adoption of electronic records management system in the Yemeni oil and gas sector," Test Engineering and Management, vol. 83, pp. 6528-6538, 2020.

[18] S. S. Al-Gahtani, "Empirical investigation of e-learning acceptance and assimilation: a structural equation model," Applied Computing and Informatics, vol. 12, no. 1, pp. 27-50, 2016.

[19] S. Ganapati, "Uses of public participation geographic information systems applications in E-government," Public Administration Review, vol. 71, no. 3, pp. 425-434, 2011.

[20] A. Murad and B. F. Khashoggi, "Using GIS for disease mapping and clustering in Jeddah, Saudi Arabia," ISPRS International Journal of Geo-Information, vol. 9, no. 5, p. 328, 2020.

[21] E. Margolis and L. Pauwels, The SAGE Handbook of Visual Research Methods, SAGE, Newcastle upon Tyne, UK, 2011.

[22] F. Mukherjee, "GIS use by an urban local body as part of e-governance in India," Cartography and Geographic Information Science, vol. 45, no. 6, pp. 556-569, 2018.

[23] M. F. Goodchild, "Reimagining the history of GIS," Annals of GIS, vol. 24, no. 1, pp. 1-8, 2018.

[24] Y.-S. Huang, S.-G. Shih, and K.-H. Yen, "An integrated GIS, BIM and facilities infrastructure information platform designed for city management," Journal of the Chinese Institute of Engineers, vol. 44, no. 4, pp. 1-12, 2021.

[25] P. A. Longley, Geographic Information Systems and Science, John Wiley \& Sons, Hoboken, NJ, USA, 2005.

[26] P. A. Longley, Geographic Information Science and Systems, John Wiley \& Sons, Hoboken, NJ, USA, 2015.

[27] F. Othman, Z. M. Yusoff, and S. A. Salleh, "Assessing the visualization of space and traffic volume using GIS-based processing and visibility parameters of space syntax," GeoSpatial Information Science, vol. 23, no. 3, pp. 209-221, 2020.
[28] M. Sztubecka, M. Skiba, M. Mrówczyńska, and A. BazanKrzywoszańska, "An innovative decision support system to improve the energy efficiency of buildings in urban Areas," Remote Sensing, vol. 12, no. 2, p. 259, 2020.

[29] G. Villacreses, G. Gaona, J. Martínez-Gómez, and D. J. Jijón, "Wind farms suitability location using geographical information system (GIS), based on multi-criteria decision making (MCDM) methods: the case of continental Ecuador," Renewable Energy, vol. 109, pp. 275-286, 2017.

[30] I. Lytvynchuk, O. Skydan, and O. Ivaniuk, "Local governance and territorial development ON the basis OF GIS," Management Theory and Studies for Rural Business and Infrastructure Development, vol. 42, no. 4, pp. 422-433, 2020.

[31] M. S. Hossain, C. K. Gadagamma, Y. Bhattacharya, M. Numada, N. Morimura, and K. Meguro, "Integration of smart watch and Geographic Information System (GIS) to identify post-earthquake critical rescue area part. I. Development of the system," Progress in Disaster Science, vol. 7, Article ID 100116, 2020.

[32] P. Bolstad, GIS Fundamentals: A First Text on Geographic Information Systems, Eider, Chavanod, France, 2016.

[33] M. Azeez, "The geographical information science (science of geo-informatics): a historical background, and the foundations of the scientific methods," in Proceedings of the 8th GIS Symposium in the Eastern Province, 2013.

[34] U. Ali, M. H. Shamsi, M. Bohacek et al., "A data-driven approach for multi-scale GIS-based building energy modeling for analysis, planning and support decision making," Applied Energy, vol. 279, Article ID 115834, 2020.

[35] A. Mollalo, L. Mao, P. Rashidi, and G. E. Glass, "A GIS-based artificial neural network model for spatial distribution of tuberculosis across the continental United States," International Journal of Environmental Research and Public Health, vol. 16, no. 1, p. 157, 2019.

[36] A. Mollalo, B. Vahedi, and K. M. Rivera, "GIS-based spatial modeling of COVID-19 incidence rate in the continental United States," The Science of the Total Environment, vol. 728, Article ID 138884, 2020.

[37] J. Dangermond, C. De Vito, and C. Pesaresi, "Using GIS in the Time of the COVID-19 Crisis, casting a glance at the future. A joint discussion," J-READING-Journal of Research and Didactics in Geography, vol. 1, 2020.

[38] S. Sarwar, R. Waheed, S. Sarwar, and A. Khan, "COVID-19 challenges to Pakistan: is GIS analysis useful to draw solutions?" The Science of the Total Environment, vol. 730, Article ID 139089, 2020.

[39] C. Flemming, The GIS Guide for Elected Official, Esri Press, San Francisco, CA, USA, 2014.

[40] S. Muzafar and N. Z. Jhanjhi, "Success stories of ICT implementation in Saudi Arabia," in Employing Recent Technologies for Improved Digital Governance, pp. 151-163, IGI Global, Harrisburg, PA, USA, 2020.

[41] S. H. Alsultan and A. A. Rahman, "Kingdom of Saudi Arabia geospatial information infrastructure - an initial study," The International Archives of the Photogrammetry, Remote Sensing and Spatial Information Sciences, vol. XL-2/W4, pp. 95-99, 2015.

[42] S. Eria and R. B. McMaster, "GIS diffusion in Uganda," International Journal of Geographical Information Science, vol. 31, no. 5, pp. 884-906, 2017.

[43] M. Abousaeidi, R. Fauzi, and R. Muhamad, "Geographic Information System (GIS) modeling approach to determine the fastest delivery routes," Saudi Journal of Biological Sciences, vol. 23, no. 5, pp. 555-564, 2016. 
[44] C. Hebert and E. D. Root, "Repurposing geographic information systems for routine hospital infection control," Advances in Health care Management, vol. 18, 2019.

[45] N. A. Pugi, H. Zainol, and A. A. Mohamad, "Determination of new bank branch location using GIS approach," in Proceedings of the Regional Conference on Science, Technology and Social Sciences (RCSTSS 2014), 2016.

[46] F. Asni, M. A. Mahamud, and J. Sulong, "Socio-economics and management of Muslim cemetery waqf using istibdal and GIS method in Penang state," Journal of Islamic Accounting and Business Research, vol. 1, pp. 1-21, 2020.

[47] T. Chaiphongpachara, "The application of geographic information system in dengue haemorrhagic fever risk assessment in Samut Songkhram province, Thailand," International Journal of GEOMATE, vol. 12, no. 30, pp. 53-60, 2017.

[48] A. C. Rürup, Strengthening Capacities for the Use of GIS in Disaster Risk Reduction, Lund University, Lund, Sweden, 2017.

[49] N. Amade, M. Painho, and T. Oliveira, "Determinants of geographic information technologies intention and adoption and Mozambique institutions' perspectives," Research Journal of Information Technology, vol. 2, no. 9, pp. 64-73, 2017.

[50] R. Sharma, S. S. Kamble, and A. Gunasekaran, "Big GIS analytics framework for agriculture supply chains: a literature review identifying the current trends and future perspectives," Computers and Electronics in Agriculture, vol. 155, pp. 103-120, 2018.

[51] I. Elkhrachy, "Flash flood hazard mapping using satellite images and GIS tools: a case study of Najran City, Kingdom of Saudi Arabia (KSA)," The Egyptian Journal of Remote Sensing and Space Science, vol. 18, no. 2, pp. 261-278, 2015.

[52] A. R. A. Alzighaibi, An Investigation into the Adoption of Geographic Information Systems (GIS) in the Public Sector, University of Canberra, Canberra, Australia, 2017.

[53] D. J. Fasteen, Factors that Influence the Adoption of Geographic Information Systems in A Professional Work Environment: A Study of the Property Assessment Profession, University of North Dakota, Grand Forks, ND, USA, 2016.

[54] M. Alqarni, Developing a Framework to Improve the Implementation of Geospatial Technology in the Planning and Delivery of Infrastructure for Residential Areas in Saudi Arabia: A Case Study of Riyadh City, Northumbria University, Newcastle upon Tyne, UK, 2017.

[55] Z. Zeng and C. B. Cleon, "Factors affecting the adoption of a land information system: an empirical analysis in Liberia," Land Use Policy, vol. 73, pp. 353-362, 2018.

[56] N. Kock, A. Jenkins, and R. Wellington, "A field study of success and failure factors in asynchronous groupware supported process improvement groups," Business Process Management Journal, vol. 5, no. 3, pp. 238-254, 1999.

[57] V. Khandewal and J. Miller, Information System Study, Opportunity Management Program, BM Corporation, New York, NY, USA, 1992.

[58] C. V. Bullen and J. F. Rockart, "A primer on critical success factors," Report (No. 1220-81), Alfred P. Sloan School of Management, Center for Information Systems Research, Massachusetts Institute of Technology (MIT), Sloan School of Management, Cambridge, MA, USA, 1981.

[59] J. Barat, "Scenario playing for critical success factor analysis," Journal of Information Technology, vol. 7, no. 1, pp. 12-19, 1992.

[60] A. Tishler, D. Dvir, A. Shenhar, and S. Lipovetsky, "Identifying critical success factors in defense development projects: a multivariate analysis," Technological Forecasting and Social Change, vol. 51, no. 2, pp. 151-171, 1996.

[61] J. Esteves and J. Pastor, "Enterprise resource planning systems research: an annotated bibliography," Communications of the Association for Information Systems, vol. 7, no. 1, p. 8, 2001.

[62] B. MacCarthy and W. Atthirawong, "Critical factors in international location decisions: a Delphi study," in Proceedings of the 12th Annual Meeting of the Production and Operations Management, Orlando, FL, USA, March 2001.

[63] J. C. Brancheau and J. C. Wetherbe, "Key issues in information systems management," MIS Quarterly, vol. 11, no. 1, pp. 23-45, 1987.

[64] M. Lawley, Critical Success Factors for Regional Community Portals: A Preliminary Model, Massey University, Palmerston, New Zealand, 2001.

[65] V. K. Khandelwal and J. R. Ferguson, "Critical success factors (CSFs) and the growth of IT in selected geographic regions," in Proceedings of the 32nd Annual Hawaii International Conference on Systems Sciences, IEEE, Los Alamitos, CA, USA, 1999.

[66] A. Parr and G. Shanks, "A model of ERP project implementation," Journal of Information Technology, vol. 15, no. 4, pp. 289-303, 2000.

[67] V. K. Khandelwal and J. R. Ferguson, "Critical success factors (CSFs) and the growth of IT in selected geographic regions," in Proceedings of the 32nd Annual Hawaii International Conference on Systems Sciences, HICSS-32. Abstracts and CDROM of Full Papers, IEEE, Honolulu, HI, USA, 1999.

[68] M. Mukred, Z. Yusof, U. A. Mokhtar, and N. Abdul Manap, "Electronic records management system adoption readiness framework for higher professional education institutions in Yemen," International Journal of Advanced Science, Engineering and Information Technology, vol. 6, no. 6, pp. 804811, 2016.

[69] F. A. Goni, "Segments and elements influenced on ERP system implementation," Australian Journal of Basic and Applied Sciences, vol. 6, no. 10, pp. 209-221, 2012.

[70] M. H. Shah and F. A. Siddiqui, "Organisational critical success factors in adoption of e-banking at the Woolwich bank," International Journal of Information Management, vol. 26, no. 6, pp. 442-456, 2006.

[71] S. Finney and M. Corbett, "ERP implementation: a compilation and analysis of critical success factors," Business Process Management Journal, vol. 13, no. 3, pp. 329-347, 2007.

[72] E. W. T. Ngai, C. C. H. Law, and F. K. T. Wat, "Examining the critical success factors in the adoption of enterprise resource planning," Computers in Industry, vol. 59, no. 6, pp. 548-564, 2008.

[73] P. Hawking and C. Sellitto, "Business Intelligence (BI) critical success factors," in Proceedings of the 21st Australian Conference on Information Systems, Brisbane, Australia, 2010.

[74] M. M. Ahmad and R. P. Cuenca, "Critical success factors for ERP implementation in SMEs," Robotics and ComputerIntegrated Manufacturing, vol. 29, no. 3, pp. 104-111, 2013.

[75] F. D. Davis, "Perceived usefulness, perceived ease of use, and user acceptance of information technology," MIS Quarterly, vol. 13, no. 3, pp. 319-340, 1989.

[76] M.-C. Lee, "Factors influencing the adoption of internet banking: an integration of TAM and TPB with perceived risk and perceived benefit," Electronic Commerce Research and Applications, vol. 8, no. 3, pp. 130-141, 2009. 
[77] V. Venkatesh and F. D. Davis, "A theoretical extension of the technology acceptance model: four longitudinal field studies," Management Science, vol. 46, no. 2, pp. 186-204, 2000.

[78] V. Aggelidis and P. Chatzoglou, "Using a modified technology acceptance model in hospitals," International Journal of Medical Informatics, vol. 78, no. 2, pp. 115-126, 2009.

[79] M. Legiawan and A. Sutoni, "The role of using gadgets in facing the existence of information systems in the tourism village community in cidadap village using TAM (technology acceptance model)," in Journal of Physics: Conference SeriesIOP Publishing, Bristol, UK, 2021.

[80] W. A. Winarno and H. S. Putra, "Technology acceptance model of the Indonesian government financial reporting information systems," International Journal of Public Sector Performance Management, vol. 6, no. 1, pp. 68-84, 2020.

[81] D. Dhagarra, M. Goswami, and G. Kumar, "Impact of trust and privacy concerns on technology acceptance in healthcare: an Indian perspective," International Journal of Medical Informatics, vol. 141, Article ID 104164, 2020.

[82] M. Mukred, Z. M. Yusof, and F. M. Alotaibi, "Ensuring the productivity of higher learning institutions through electronic records management system (ERMS)," IEEE Access, vol. 7, pp. 97343-97364, 2019.

[83] J.-G. Lay, Y.-W. Chen, and Y.-L. Chi, "GIS adoption among senior high school geography teachers in Taiwan," Journal of Geography, vol. 112, no. 3, pp. 120-130, 2013.

[84] Y. bin Arshad and M. S. bin Mohd Sani, "Geographical information system (GIS) as an innovative adoption to ease customers in locating SME business premises in Malacca," in Proceedings of the MATEC Web of Conferences, November 2018.

[85] E. Häggquist and I. Nilsson, "Factors influencing the adoption of geological information in Swedish municipalities," Journal of Environmental Planning and Management, vol. 60, no. 6, pp. 1112-1126, 2017.

[86] G. E. Baraka and S. K. Murimi, "Stuck in the past with pushpins on paper maps: challenges of transition from manual to computerized crime mapping and analysis in Kenya," International Journal of Police Science and Management, vol. 21, no. 1, pp. 36-47, 2019.

[87] W. H. DeLone and E. R. McLean, "Information systems success: the quest for the dependent variable," Information Systems Research, vol. 3, no. 1, pp. 60-95, 1992.

[88] N. Gorla, T. M. Somers, and B. Wong, "Organizational impact of system quality, information quality, and service quality," The Journal of Strategic Information Systems, vol. 19, no. 3, pp. 207-228, 2010.

[89] M. Mukred and Z. M. Yusof, "The DeLone-McLean information system success model for electronic records management system Adoption in higher professional education institutions of Yemen," in Proceedings of the International Conference of Reliable Information and Communication Technology, Springer, Johor, Malaysia, April 2017.

[90] H. Paggi, J. Soriano, J. A. Lara, and E. Damiani, "Towards the definition of an information quality metric for information fusion models," Computers \& Electrical Engineering, vol. 89, Article ID 106907, 2021.

[91] W. H. Delone and E. R. McLean, "The DeLone and McLean model of information systems success: a ten-year update," Journal of Management Information Systems, vol. 19, no. 4, pp. 9-30, 2003.

[92] Sánchez and J. C. Prieto, "Exploring the unknown: the effect of resistance to change and attachment on mobile adoption among secondary preservice teachers," British Journal of Educational Technology, vol. 50, no. 5, pp. 2433-2449, 2019.

[93] T. Huang and K. Yasuda, "Comprehensive review of literature survey articles on ERP," Business Process Management Journal, vol. 22, no. 1, pp. 2-32, 2016.

[94] A. Azadeh, M. A. Mofrad, and M. Khalojini, "The role of organisational infrastructure in successful ERP implementation: an empirical study by hierarchical regression and PCA," International Journal of Business Information Systems, vol. 10, no. 1, pp. 40-67, 2012.

[95] C. Cartman and A. Salazar, "The influence of organisational size, internal IT capabilities, and competitive and vendor pressures on ERP adoption in SMEs," International Journal of Enterprise Information Systems, vol. 7, no. 3, pp. 68-92, 2011.

[96] L. Collins and J. T. Mitchell, "Teacher training in GIS: what is needed for long-term success?" International Research in Geographical \& Environmental Education, vol. 28, no. 2, pp. 118-135, 2019.

[97] F. Al Mamun, "Predictive factors of insomnia during the COVID-19 pandemic in Bangladesh: a GIS-based nationwide distribution," Sleep Medicine, vol. 21, pp. 1389-9457, 2021.

[98] X. Chen and W. Chen, "GIS-based landslide susceptibility assessment using optimized hybrid machine learning methods," Catena, vol. 196, Article ID 104833, 2021.

[99] I. Arpaci, "A hybrid modeling approach for predicting the educational use of mobile cloud computing services in higher education," Computers in Human Behavior, vol. 90, pp. 181-187, 2019.

[100] L. J. L. Canillo and A. A. Hernandez, "User acceptance of flood risk visualization and prediction information system," International Journal of Enterprise Information Systems, vol. 17, no. 3, pp. 16-33, 2021.

[101] V. Vathanophas, N. Krittayaphongphun, and C. Klomsiri, "Technology acceptance toward e-government initiative in Royal Thai Navy," Transforming Government: People, Process and Policy, vol. 2, no. 4, pp. 256-282, 2008.

[102] Z. Zeng, S. Li, J.-W. Lian, J. Li, T. Chen, and Y. Li, "Switching behavior in the adoption of a land information system in China: a perspective of the push-pull-mooring framework," Land Use Policy, vol. 109, Article ID 105629, 2021.

[103] Y. A. Sayed and M. E. Fadl, "Agricultural sustainability evaluation of the new reclaimed soils at Dairut Area, Assiut, Egypt using GIS modeling," The Egyptian Journal of Remote Sensing and Space Science, 2021, In press.

[104] K. K. Adu and P. Ngulube, "Key threats and challenges to the preservation of digital records of public institutions in Ghana," Information, Communication \& Society, vol. 20, no. 8, pp. 1127-1145, 2017.

[105] L. C. Tagliabue, F. Re Cecconi, N. Moretti, S. Rinaldi, P. Bellagente, and A. L. C. Ciribini, "Security assessment of urban areas through a gis-based analysis of lighting data generated by IoT sensors," Applied Sciences, vol. 10, no. 6, p. 2174,2020 .

[106] F. F.-H. Nah, K. M. Zuckweiler, and J. Lee-Shang Lau, "ERP implementation: chief information officers' perceptions of critical success factors," International journal of Humancomputer Interaction, vol. 16, no. 1, pp. 5-22, 2003.

[107] U. Remus, "Critical success factors for implementing enterprise portals," Business Process Management Journal, vol. 13, no. 4, pp. 538-552, 2007.

[108] L. Seymour, W. Makanya, and S. Berrangé, "End-users' acceptance of enterprise resource planning systems: an 
investigation of antecedents," in Proceedings of the 6th Annual ISOnEworld Conference, Las Vegas, NV, USA, 2007.

[109] S. Henrico, S. Coetzee, A. Cooper, and V. Rautenbach, "Acceptance of open source geospatial software: assessing QGIS in South Africa with the UTAUT2 model," Transactions in GIS, vol. 25, no. 1, pp. 468-490, 2021. 